\title{
Publisher Correction: Impact of type of minimally invasive approach on open conversions across ten common procedures in different specialties
}

\author{
Paresh C. Shah ${ }^{1} \cdot$ Alexander de Groot ${ }^{2} \cdot$ Robert Cerfolio $^{3} \cdot$ William C. Huang ${ }^{4} \cdot$ Kathy Huang $^{5} \cdot$ Chao Song $^{2} \cdot$ Yanli Li $^{2}$. \\ Usha Kreaden ${ }^{2} \cdot$ Daniel S. Oh ${ }^{6}$
}

Published online: 25 February 2022

(c) The Author(s) 2022

\section{Correction to: Surgical Endoscopy https://doi.org/10.1007/s00464-022-09073-5}

This article was updated to correct the author affiliations for Alexander de Groot and Robert Cerfolio.

Publisher's Note Springer Nature remains neutral with regard to jurisdictional claims in published maps and institutional affiliations.

The original article can be found online at https://doi.org/10.1007/ s00464-022-09073-5

Daniel S. Oh

Daniel.Oh@med.usc.edu

1 Division of General Surgery, Department of Surgery, Robert I. Grossman School of Medicine, New York University, New York, NY, USA

2 Department of Global Access Value Economics, Intuitive, Sunnyvale, CA, USA

3 Division of Thoracic Surgery, Department of Cardiothoracic Surgery, Robert I. Grossman School of Medicine, New York University, New York, NY, USA

4 Division of Urologic Oncology, Department of Urology, Robert I. Grossman School of Medicine, New York University, New York, NY, USA

5 Division of Gynecologic Oncology, Department of Obstetrics and Gynecology, Robert I. Grossman School of Medicine, New York University, New York, NY, USA

6 Division of Thoracic Surgery, Department of Surgery, Keck School of Medicine, University of Southern California, 1510 San Pablo St, Los Angeles, CA 90033, USA 